\title{
Utilitarian Cycling in Belgium: A Cross-Sectional Study in a Sample of Regular Cyclists
}

\author{
Bas de Geus, Bart Degraeuwe, Grégory Vandenbulcke, Luc Int Panis, \\ Isabelle Thomas, Joris Aertsens, Yves De Weerdt, Rudi Torfs, and Romain Meeusen
}

\begin{abstract}
Background: For an accurate estimation of health benefits and hazards of utilitarian cycling, a prospective collection of bicycle usage data (exposure) is fundamental. Individual and environmental correlates are necessary to guide health promotion and traffic safety issues. Firstly, this study aims to report on utilitarian bicycle usage in Belgium, using a prospective data collection in regular adult commuter cyclists. Secondly, the association is explored between the individual variation in bicycle usage and individual and environmental correlates. Methods: 1187 regular adult cyclists filled out travel diaries prospectively. Multivariate linear regression with Stepwise selection (SMLR) models studied the association between exposure and individual and environmental correlates. Results: Higher age and availability of cycle paths have a positive association with bicycle usage to work. Women cycle significant less compared with men, and so do cyclists with 'poor' or 'average' health. Living in an urban crown (opposed to city center) and living in Flanders (opposed to Brussels or Wallonia) is associated with significantly more cycling. Conclusions: Utilitarian cycling is related to regional differences, level of urbanization of the place of residence, availability of bicycle paths, and gender. These findings are useful in estimating health benefits and hazards of utilitarian cycling among regular Belgian cyclists.
\end{abstract}

Keywords: bicycle usage, correlates, prospective, SHAPES

Research on physical activity and health provides continuing, consistent and increasingly specific evidence to support the importance of physical activity for public health. ${ }^{1,2}$ To promote and maintain health, all healthy adults aged $18-65$ years need moderateintensity aerobic (endurance) physical activity (PA) for a minimum of $30 \mathrm{~min}$ on 5 days each week or vigorous-intensity aerobic PA for a minimum of 20 min on 3 days each week. ${ }^{3,4}$ Other authors have suggested that even half the recommended amount of physical activity (ie, 15 min per day or 90 min a week of moderate-intensity exercise) can provide significant health benefits. ${ }^{5}$

Utilitarian cycling (ie, cycling for transportation) has been identified as an important strategy for reducing inactivity and improving cardiorespiratory fitness and mental health, ${ }^{6-10}$ because it holds the potential of being physically active on a regular basis at a moderate to vigorous intensity. ${ }^{11}$ Hendriksen et $\mathrm{al}^{8}$ and de Geus et $\mathrm{al}^{9}$ showed a positive dose-response relationship between the amount of cycling and health outcomes, in previously sedentary subjects. The lower the physical performance at the start of the study and the higher the total amount of kilometers cycled, the higher the gain in maximal external power (Wmax). ${ }^{8}$ The maximal oxygen consumption increased significantly at approximately $1000 \mathrm{kcal} /$ week and 1500 $\mathrm{kcal} /$ week of energy expended while cycling for women and men, respectively. ${ }^{9}$ Additionally, cycling is increasingly being promoted as a mean to reduce traffic congestion, air and noise pollution and the consumption of fossil fuels. ${ }^{12}$

de Geus and Meeusen are with the Dept of Human Physiology, Vrije Universiteit Brussel, Brussels, Belgium. Degraeuwe, Int Panis, Aertsens, De Weerdt, and Torfs are with the Dept of Transport \& Mobility, Flemish Institute for Technological Research (VITO), Mol, Belgium. Vandenbulcke and Thomas are with C.O.R.E. and the Dept of Geography, Université Catholique de Louvain (UCL), Louvain-La-Neuve, Belgium.
To estimate the health impact of utilitarian cycling (as a resultant of being physically active, inhalation of air pollution and risk of bicycle accidents) an in-depth and thorough collection of bicycle usage (exposure) data are essential. ${ }^{12}$ As was shown by Int Panis et $\mathrm{al},{ }^{12}$ the dose of inhaled pollutants is dependent on the physical effort and so indirectly from cycling speed. Exposure-based injury and fatality rates will help us to understand whether policies reduce exposure or whether they increase risk, given a similar level of exposure. ${ }^{13}$ Without exposure data, the incidence rate cannot be calculated, making comparisons between countries or regions within 1 country difficult. ${ }^{14}$

In most countries, statistics on bicycle usage (cycling time, speed and distance) are not collected in a systematic way and are often restricted to modal share or trip share and thus represent a weak indicator of exposure. ${ }^{15}$ Exceptions are the UK (UK Dept. of Transport) and the Netherlands (Centraal Bureau voor de Statistiek). In Belgium, the most recent nationwide dataset on bicycle usage was collected within the framework of the national socioeconomic census carried out in 2001 by the National Institute for Statistics. ${ }^{16}$ Vandenbulcke et $\mathrm{al}^{17}$ showed large differences in bicycle usage between the 3 institutional regions, caused by differences in topography (flat vs. hilly terrain), urban structure (Brussels-Capital Region vs. Flanders and Wallonia) and bicycle culture. Although exhaustive, these data have become outdated due to the rapid evolution in traffic density and changes in modal share. In addition, bicycle exposure data are mostly collected in a retrospective way, which could be subject to recall bias.

Developing policies that increase cycling rates and result in a safer cycling environment requires knowledge of correlates that influence bicycle usage. ${ }^{18}$ Previous studies have shown the importance of individual and environmental correlates to explain bicycle usage. ${ }^{18-22}$

Firstly, this study aims to report on utilitarian bicycle usage in Belgium, using a prospective data collection in regular adult com- 
muter cyclists. Secondly, the association is explored between the individual variation in bicycle usage and individual and environmental correlates. Attention was particularly put on the role played by the institutional region of the place of residence as regional differences in Belgium form microcosms that also reflect variation observed at other geographical levels, between European countries (eg, northern and southern) or between different states within the USA. ${ }^{13}$

\section{Methods}

\section{Study Design}

This study is part of the SHAPES project (Systematic analysis of Health risks and physical Activity associated with cycling PoliciES) which is at the crossroads of health, transport and air pollution research. The aim of the SHAPES project is to analyze the benefits and risks (voluntary and involuntary) of cycling and to advise policy makers to facilitate the implementation of intersectoral policies related to cycling for transport. Within the SHAPES project exposure to traffic exhaust and accidents during cycling were considered as risks (see ${ }^{12,17,22-24}$ ).

For this part of the SHAPES project, bicycle usage data (exposure) were collected prospectively during 1 year, and were then correlated cross-sectionally with environmental and self-reported individual factors. A web and e-mail-based registration system to establish a cohort of commuter cyclists was incorporated in the website of the SHAPES project: www.shapes-ssd.be. The SHAPES online registration system was open-access, so that anyone could access the website and participate if they passed the inclusion and exclusion criteria. The system was designed to register bicycle usage and its (potential) individual and environmental correlates. Utilitarian cycling was here defined as 'commuting to or from work' or 'cycling to other destinations.' Leisure and 'sports-related' cycling (eg, cycling for competition or cycling that is not done for an utilitarian purpose such as work) was excluded. After entering their e-mail address, an automatically generated e-mail was sent to the tentative participant. In this first e-mail, information related to the purpose of the online registration system was given. The inclusion criteria were checked: (1) age between 18-65 years, (2) having a paid job outside home, (3) cycling to work at least twice a week for the preceding year, and (4) living in Belgium (Western Europe).

Those who fulfilled the inclusion criteria, further referred to as 'participants,' got access to the General Questionnaire (section 2.4.). At the same moment, a second e-mail was sent including the first travel diary (TD), which was resent to the participants every week (see section 2.3.). The General Questionnaire was filled out at one occasion, together with the first travel diary. The main dataset for this study was collected between March 10, 2008 and March 16, 2009.

The Vrije Universiteit Brussel Ethical Committee approved the study protocol.

\section{Studied Area}

Belgium is subdivided into 3 institutional regions: the BrusselsCapital region (BCR, central), the Flemish region (north), and the Walloon region (south). Although the traffic legislation is the same in the 3 institutional regions, procycling measures are more frequently implemented in Flanders: traffic calming measures are more frequent, traffic speed on secondary roads is more limited, bicycle infrastructure is more readily available, and road- and cityplanning pay more attention to cyclists. ${ }^{17}$ The BCR is a particular region as it consists of a single condensed urbanized built-up area.
Data from the Belgian 'National household survey'16, showed a clear-cut north-south division in bicycle usage, infrastructure, the presence of probicycle policies, flat $v s$. hilly terrain, and attitude toward cycling (for details, see Vandenbulcke et al. ${ }^{1,22}$ ).

\section{Bicycle Usage}

Travel diaries (TD) were filled out prospectively on a weekly basis to collect self-reported data on bicycle usage. The same TD was used in other studies. ${ }^{9,10}$ All participants that fulfilled the inclusion criteria received an automatically generated e-mail every week at the same moment (Monday at $2 \mathrm{AM}$ ) with the question to fill out 1 unique TD. Data on travel frequency, time spent cycling and distance traveled over the past 7 days was collected. Average cycling speed was calculated per week using the total travel time and total distance cycled during that specific week. In the TDs a distinction was made between 'cycling to and from work' and 'cycling to other destinations' (eg, cycling to the grocery shop, but excluding cycling for leisure and sport purposes).

Oja et $\mathrm{al}^{25}$ have emphasized the importance of the total energy expenditure of PA rather than its specific characteristics such as intensity, frequency, and bout duration for health benefits. Estimated total energy expenditure (MET-min/week) for each participant was used as the dependent variable and calculated by multiplying the bout duration (time spent cycling per week) with the intensity (cycling speed) to obtain an useful measure of bicycle usage. The cycling speed from the TD's of every individual cyclist was then converted to Metabolic Equivalents (MET) according to Ainsworth et al. ${ }^{26} \mathrm{MET}$ is an index of energy expenditure. [A MET is] the ratio of the rate of energy expended during an activity to the rate of energy expended at rest. [One] MET is the rate of energy expenditure while sitting at rest by convention.

MET-minutes is an index of energy expenditure that quantifies the total amount of physical activity performed in a standardized manner across individuals and types of activities. Calculated as the product of the number of METs associated with 1 or more physical activities and the number of minutes the activities were performed (ie, METs $\times$ minutes). Usually standardized per week or per day. Example: cycling at $18 \mathrm{~km} / \mathrm{h}(=6 \mathrm{METs})$ for $30 \mathrm{~min}$ on $3 \mathrm{~d} / \mathrm{wk}$ : 6 METs $\times 30 \mathrm{~min} \times 3$ times per week $=540 \mathrm{MET}-\mathrm{min} / \mathrm{wk}$.

\section{Individual and Environmental Correlates}

The individual and environmental correlates were collected through the General Questionnaire, that is based on the Belgian National Household Survey on Mobility ${ }^{16}$ and recent literature (eg, Winters et $\mathrm{al}^{18}$ and Moudon et $\mathrm{al}^{20}$ ). Individual (gender, age, body mass index (BMI), perceived health, education, work situation and children) and environmental (availability of bicycle paths, level of urbanization of the place of residence (denoted as 'Urbanization Home') and level of urbanization of the work place (denoted as 'Urbanization Work'), region of the place of residence (denoted as 'Region Home') and region of the work place (denoted as 'Region Home') correlates were studied. Supplementary File 1 lists and describes the explanatory variables.

To determine the correlates of bicycle usage, a Multivariate Linear Regression with Stepwise selection (SMLR), using Ordinary Least Square (OLS) estimation, was performed with MET-min/ week as the continuous dependent variable. MET-min/week was $\ln$ transformed to fulfill the assumptions of OLS multivariate linear regression. The following assumptions were met: strictly exogenous independent variables, absence of multicollinearity, normally distributed, homoscedastic and nonautocorrelated errors and finite error 
variances. Multicollinearity between 'Region Home' and 'Region Work' (Spearman correlation coefficient: 0.64; $P<.0001$ ) and 'Urbanization Home' and 'Urbanization Work' (Spearman correlation coefficient: $0.31 ; P<.0001$ ) was present and therefore 'Region Work' and 'Urbanization Work' were not included in the SMLR. 'Education' and 'work situation' were also discarded because only $10.2 \%$ of the participants did not finish university studies and only $2.5 \%$ were "blue collar" workers.

A separate SMLR analysis was performed for (1) 'cycling to work' and for (2) 'cycling to other destinations.' This distinction was made because previous research indicated the importance of differentiating between context-specific behaviors. ${ }^{27}$

\section{Results}

\section{Study Population}

After 1 year of open-access, 1849 participants had left their e-mail address on the SHAPES server. Three hundred and seventy-seven of these participants did not respond to the first mail that asked them about the inclusion criteria and the General Questionnaire (GQ); 29 participants did not live in Belgium; 23 did not fit the age group (and were $<18$ years old or $>65$ years old); 116 did not have a paid job; and 101 did not cycle to work 2 or more times a week. That left us with $1203(65.1 \%)$ participants that filled out the GQ. One thousand one hundred and eighty-seven participants filled out more than 1 travel diaries (TD) and were included in the data analysis.
Characteristics of our study population can be found in de Geus et $\mathrm{al}^{24}$ where they were compared with those of the 'National household survey on mobility'. ${ }^{16}$ Participants in this study form a particular cohort composed of regular mostly male $(68.2 \%)$ commuter cyclists $(74.5 \%$ use the bicycle throughout the whole year) who are in good health $(92.8 \%$ indicate to be in good to very good health), had a higher level of education (89.2\%), and have a higher job status (only $2.5 \%$ blue collar workers). In comparison with the data of the National Institute for Statistics (NIS, 2001), ${ }^{16}$ significantly $(P<.05)$ more participants in this study are men, have a higher education and significantly $(P<.05)$ less participants are blue collar workers.

Figure 1 shows the spatial distribution of the SHAPES participants, per municipality of residence. Thirty-five percent, $50 \%$, and $15 \%$ of the total number of participants live in the BCR, Flanders, and Wallonia, respectively (Table 1).

\section{Bicycle Usage}

In total, 20,107 TDs were retained for data analysis. Within the first 6 weeks almost $50 \%$ of the total number of participants had registered. After these 6 weeks, the number of new entries and participants who stopped their participation stayed nearly constant for the rest of the study period (see Aertsens et $\mathrm{al}^{23}$ for details). Over 1 year, on average 387 TDs per week were filled out, representing 20.3 \pm 16.7 TDs per participant. In BCR and Wallonia, every participant filled out 18.8 \pm 16.4 and $18.6 \pm 15.5$ TDs respectively. In Flanders, significantly more $(P<.05)$ TDs were returned per participant $(21.9 \pm 17.1$ TDs $)$.

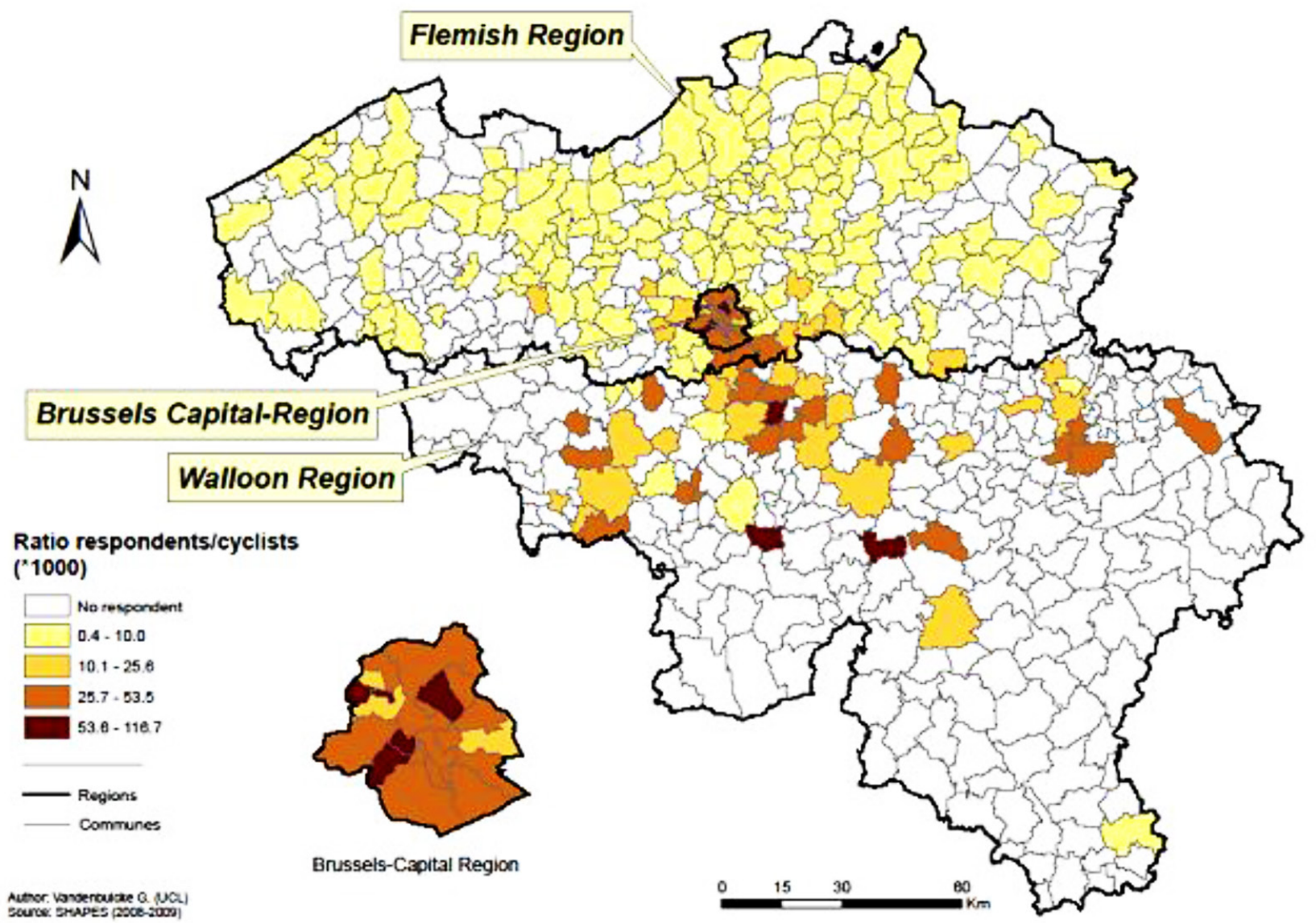

Figure 1 - Ratio between SHAPES participants and 'cyclists living in Belgium' (NIS, 2001). 
Table 1 Studied Area

\begin{tabular}{|c|c|c|c|}
\hline Characteristic & BCR & Flanders & Wallonia \\
\hline Location & Central & North & South \\
\hline$\%$ inhabitants & $10 \%$ & $58 \%$ & $32 \%$ \\
\hline Population density (inhab/km²) & 6497 & 456 & 205 \\
\hline Bicycle infrastructure/ probicycle policies ${ }^{21,24}$ & + & ++ & - \\
\hline Urbanization $^{21,24}$ & ++ & + & - \\
\hline Topography & Hilly & Flat & Very hilly \\
\hline \multicolumn{4}{|l|}{ Model share bicycle } \\
\hline $2001^{16}$ & $1 \%$ & $12 \%$ & $2 \%$ \\
\hline $2005 \rightarrow 2008^{46}$ & $1.2 \% \rightarrow 1.5 \%$ & $12.1 \% \rightarrow 12.9 \%$ & $1.2 \% \rightarrow 1.5 \%$ \\
\hline $2000 \rightarrow 2009^{16,47}$ & $1 \% \rightarrow 4 \%$ & / & / \\
\hline
\end{tabular}

Note. / = data not available; "+” and "_" = present or not.

Abbreviations: BCR, Brussels Capital Region.

The total distance and time covered were $1,474,978 \mathrm{~km}$ and 78,099 hours of utilitarian cycling. Of this total, 1,116,295 km (76\%) and 57,235 (73\%) hours was 'cycling to work' and 358,683 km (24\%) and 20,864 hours (27\%) was 'cycling to other destinations.'

\section{Bicycle Usage by Gender}

For the trips to work, men cycled significantly $(P<.01)$ more in terms of traveled time $(+31 \%)$ and distance $(+70 \% \mathrm{~km} /$ week and $+74 \% \mathrm{~km} /$ trip $)$ and cycled significantly $(P<.01)$ faster $(+26 \%)$ and spend significantly $(P<.01)$ more $(+92 \%)$ energy than women (Table 2). Except for time per week, the same was true for cycling to 'other' destinations.

\section{Bicycle Usage By Region}

The average cycling characteristics of our study population confirm the large regional difference in bicycle usage (Table 3 ). Flanders is the Belgian region where the mean time and distance per week and total cycled distance are significantly $(P<.05)$ higher compared with the 2 other regions. Cycling speed in the BCR was significantly $(P$ $<.01)$ lower, compared with the 2 other regions. Participants from the Walloon region cycled a significantly $(P<.01)$ smaller number of trips per week. The same trends are present when looking at male and female participants, respectively.

\section{Association Between Individual and Environmental Correlates and Bicycle Usage}

Cycling to and From Work. The model predicts the dependent variable significantly $(F=38.41, P<.0001)$ and accounts for $26 \%$ of the variance in bicycle usage for cycling to work (adjusted $R^{2}=$ .2641), indicating that a notable amount of variance of the dependent variable remains unexplained.

There is a positive association between bicycle usage to work and the presence of more cycle paths $(\beta=0.10329, P=.0030)$ and higher age $(\beta=0.10163, P=.0013)$. Women have a significantly lower bicycle usage than men $(\beta=-0.20753, P<.0001)$, and so do cyclists with 'poor' or 'average' health compared with '(very) good' health $(\beta=-0.07902, P=.0088)$. Living in an urban crown (as opposed to living in the city center) $(\beta=0.21259, P<$ .0001 ) and living in Flanders (as opposed to living in Brussels or Wallonia) is associated with significantly more bicycle usage $\left.\left(\beta_{\text {Brussels }}=-0.19897, P<.0001\right), \beta_{\text {Wallonia }}=-0.17217, P<.0001\right)$ (Table 4).

In other words, this model shows that bicycle usage to work (MET-min/week) is mostly associated with 'gender' and the 'level of urbanization.' 'Living in Flanders' follows as the independent variable that mostly predicts bicycle usage.

Cycling to 'Other' Destinations. Although the model fits the data significantly $(F=8.58, P<.0001)$, the independent variables only explain $4.5 \%$ of the variability of the dependent variable (adjusted $R^{2}=.0449$; Table 5). This indicates that the variables entered in the model leave most of the variance of the dependent variable unexplained.

'Age' $(\beta=0.15403, P<.0001)$ and 'children' $(\beta=0.10262, P$ $=.0054$ ) both have a significant positive association with MET-min/ week cycled to 'other' destinations. The bicycle usage to 'other' destinations in Brussels and Wallonia is significantly lower than in Flanders $\left(\beta_{\text {Brussels }}=-0.08248, P=.0249\right.$ and $\beta_{\text {Wallonia }}=-0.15516$, $P<.0001$, with Flanders as respective reference level).

The model shows that living in Flanders is associated with a larger amount of bicycle usage to 'other' destinations (MET-min/ week), compared with living in Wallonia. 'Age' is the second strongest predictor in the model. Older people tend to cycle more to other destinations compared with younger people.

\section{Discussion}

To our knowledge, this is the first prospective data collection for a period of 1 year, that involves a relatively large group of regular adult cyclists $(\mathrm{N}=1187)$, mainly using the bicycle for transport purposes. The SHAPES registration system was able to cover a total of 20,107 weeks by asking volunteers to report on their weekly travel frequency, time and distance, using an online recruitment procedure.

This paper provides data that will enable a better estimation and understanding of the potential health benefits and hazards of utilitarian cycling in regular cyclists and will be useful to guide policy initiatives for mobility, targeted health promotion, transportation infrastructure and traffic safety issues.

\section{Bicycle Usage}

Bicycle Usage By Gender. As in many other studies, ${ }^{17,18,20,28,29}$ gender is a strong explanatory variable of bicycle usage. This study 


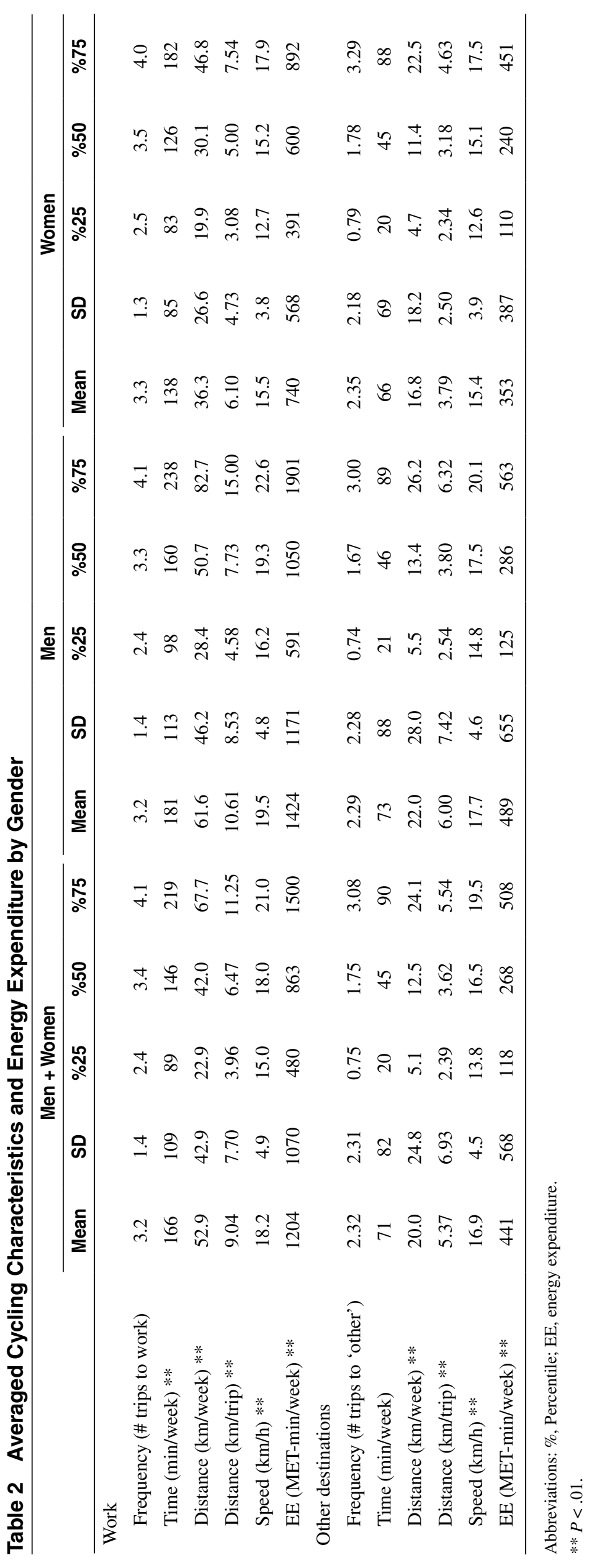




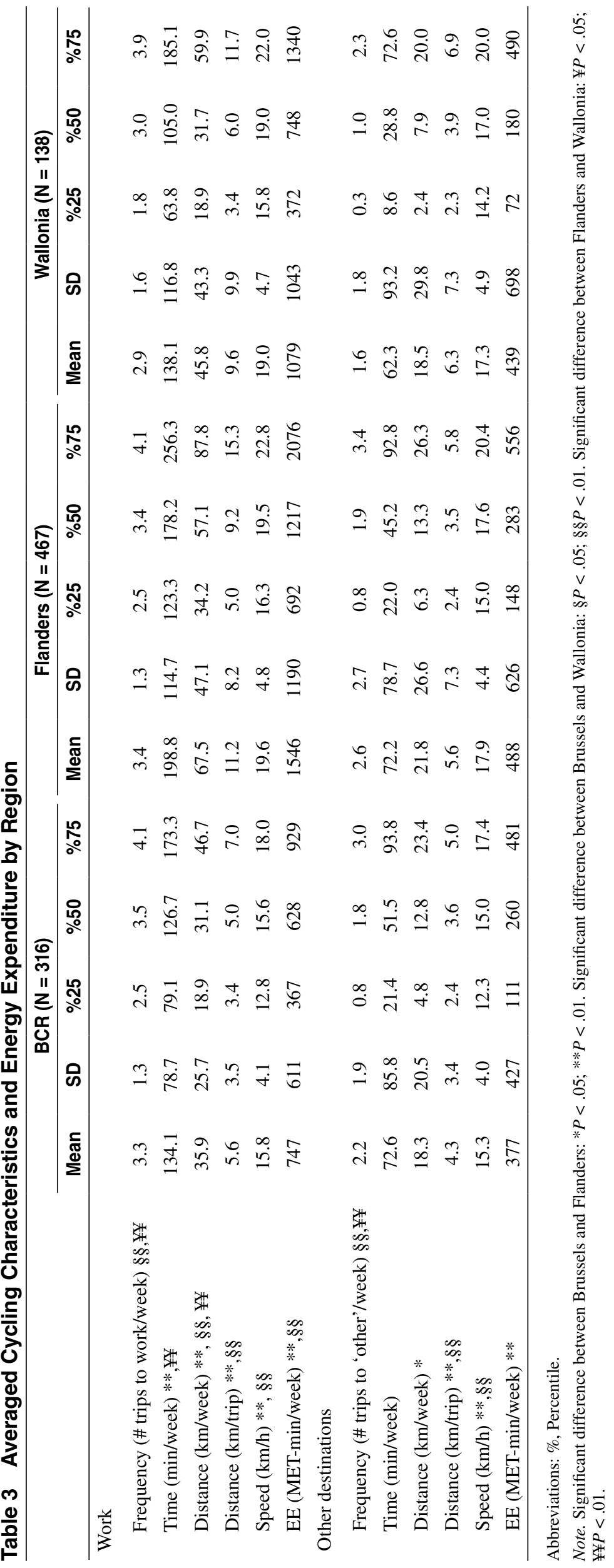




\begin{tabular}{|c|c|c|c|c|c|}
\hline Variable & $\begin{array}{l}\text { Parameter } \\
\text { estimate }(\boldsymbol{\beta})\end{array}$ & $\begin{array}{l}\text { Standard error } \\
\text { (SE) }\end{array}$ & $\begin{array}{l}\text { Standardized } \\
\text { estimate }(\beta)\end{array}$ & $t$-Value & $\boldsymbol{P}$ \\
\hline Intercept & 5.81688 & 0.24420 & 0 & 23.82 & $<0.0001$ \\
\hline Gender & -0.39467 & 0.05972 & -0.20753 & -6.61 & $<0.0001$ \\
\hline Age & 0.00897 & 0.00278 & 0.10163 & 3.23 & 0.0013 \\
\hline BMI & 0.01696 & 0.00960 & 0.05683 & 1.77 & 0.0777 \\
\hline Health & -0.26596 & 0.10135 & -0.07902 & -2.62 & 0.0088 \\
\hline Bicycle paths & 0.08617 & 0.02890 & 0.10329 & 2.98 & 0.0030 \\
\hline Region home (BCR) & -0.37031 & 0.06820 & -0.19897 & -5.43 & $<0.0001$ \\
\hline Region home (Wallonia) & -0.43615 & 0.08593 & -0.17217 & -5.08 & $<0.0001$ \\
\hline Urbanization home & 0.15122 & 0.02290 & 0.21259 & 6.60 & $<0.0001$ \\
\hline
\end{tabular}

Note. $F=38.41(P<.0001) ; R^{2}=.2711 ;$ Adjusted $R^{2}=.2641$. Parameter estimates for model with bicycle paths and Urbanization $=$ ordinal variables; Region home $=$ nominal variable (with Flanders as reference level).

Abbreviations: B, Unstandardized coefficients; SE, standard errors of the unstandardized $b_{i}$ 's; $\beta$, standardized coefficients.

\section{Table 5 Explanatory Factors of Bicycle Usage During Trips to 'Other' Destinations Assessed by} Multivariate Regression Model

\begin{tabular}{|c|c|c|c|c|c|}
\hline Variable & $\begin{array}{c}\text { Parameter } \\
\text { estimate }(\boldsymbol{\beta})\end{array}$ & $\begin{array}{l}\text { Standard error } \\
\text { (SE) }\end{array}$ & $\begin{array}{c}\text { Standardized } \\
\text { estimate }(\beta)\end{array}$ & $t$-Value & $\boldsymbol{P}$ \\
\hline Intercept & 4.86232 & 0.20125 & 0 & 24.16 & $<.0001$ \\
\hline Gender & -0.16373 & 0.08947 & -0.06431 & -1.83 & 0.0676 \\
\hline Age & 0.01813 & 0.00434 & 0.15403 & 4.18 & $<.0001$ \\
\hline Children & 0.24230 & 0.08690 & 0.10262 & 2.79 & 0.0054 \\
\hline Region home (BCR) & -0.20475 & 0.09114 & -0.08248 & -2.25 & 0.0249 \\
\hline Region home (Wallonia) & -0.52698 & 0.12260 & -0.15516 & -4.30 & $<.0001$ \\
\hline
\end{tabular}

Note. $F=8.58(P<.0001) ; R^{2}=.0508$; Adjusted $R^{2}=.0449$. Parameter estimates for model with bicycle paths and Urbanization $=$ ordinal variables; Region home $=$ nominal variable (with Flanders as reference level).

Abbreviations: B, Unstandardized coefficients; SE, standard errors of the unstandardized $b_{i}$ 's; $\beta$, standardized coefficients.

confirms that men cycled significantly more $(P<.01)$ in terms of traveled time and distance $(P<.01)$ compared with women. Comparable results are found in other countries where cycling is not part of the everyday transport culture. For example in Canada ${ }^{18,30}$ and in the USA, ${ }^{31}$ women are only half as likely as men to cycle for transportation purposes. In countries where cycling is part of the transport culture, like in the Netherlands ${ }^{32}$ and Denmark, ${ }^{33}$ women cycle more than men. The Portland (Oregon) metropolitan area has the highest rate of women biking to work in the USA. ${ }^{34}$ Notably, Portland's bicycle transportation system is recognized as being among the best large city system in North America.

Population-wide policy strategies should focus on encouraging women to use the bicycle as a transportation mode. These policy actions should contain 'soft' (communication/education) and 'hard' (enforcement/infrastructure) methods and should be used simultaneously. ${ }^{35}$ The cycling behavior of women can be considered an indicator for bike-friendly cities or countries for several reasons. First, studies across disciplines as disparate as criminology and child rearing have shown that women are more averse to risk than men. ${ }^{29}$ Risk aversion translates into increased demand for safe bike infrastructure and bicycle friendly policies (eg, bicycle paths and lanes, traffic calming, incorporating greater cycling-awareness among motorists, for example, through motor vehicle license-testing) as a prerequisite for cycling. Women also do most of the child care and household shopping, which means that bike routes need to be organized around practical urban destinations. Consistent with gender differences in risk aversion, female commuter cyclists preferred to use routes with maximum separation from motorized traffic. ${ }^{29}$ Improved cycling infrastructure in the form of bicycle paths and lanes that provide a high degree of separation from motor traffic is likely to be important for increasing utilitarian cycling among under-represented population groups such as women. ${ }^{29}$ Mass-media promotion, both of cycling and also of mutual respect between cyclists and motorists should be financed by governmental bodies. Last but not least, road safety measures (eg, avoiding speeding and distracted driving) should be enforced by law and violations of traffic rules should be punished more effectively.

\section{Bicycle Usage by Region}

Significant regional differences exist in terms of bicycle use. In the Walloon region, participants cycle less frequently to work compared with the 2 other regions, mainly because of larger distances to work, absence of cycling infrastructures and because of important slopes. ${ }^{17}$ BCR has the lowest cycling speed, which is due to the highly urbanized and dense built-up area, resulting in a high proximity and mix of activities ${ }^{17}$ making stops for traffic lights, intersections and other road users more frequent. In the Flemish region, participants cycled 
a significantly greater time and distance (both per week and per single trip). Although no cause and effect relationship can be drown with these data, results from the General Questionnaire showed that there is a significant difference $\left(\mathrm{Chi}^{2} P<.001\right)$ between Flanders on the one hand and the BCR and Wallonia on the other hand when looking at the percentage of participants that indicated they have a bicycle path or lane near their home or workplace. Policy makers in BCR and Wallonia are therefore urged to providing more bicycle facilities, to increase the number of cyclists. As Vandenbulcke et $\mathrm{al}^{17}$ indicated in their policy recommendations, engineering can be very effective in increasing bicycle use and making it safer through better development, design and maintenance of cycling infrastructures, especially in areas where it is currently lacking (Wallonia and $\mathrm{BCR}$ ). Providing traffic-calming areas or safe crossings for cyclists, as well as implementing routes that reduce exposure to pollutants, are some examples of such measures. ${ }^{12,17}$

\section{Explanatory Factors of Bicycle Usage}

In this study, 'Urbanization level of the place of residence' was the strongest predictor of bicycle usage, indicating that living in an urban crown is more attractive to cycling in comparison with living in a city center. This can partly be explained by the fact that in large cities, walking is frequent due to the close proximity of different places/activities. ${ }^{17}$ Public transport is also well-developed (eg, dense network, high frequency, comfort) and hence competes strongly with cycling. In large cities such as Brussels, the distance between the place of residence (or work) and the closest public transport stop/ station is generally short: approximately $96 \%$ of the inhabitants (and jobs) are located less than $500 \mathrm{~m}$ from the closest public transport stop. ${ }^{36}$ Opportunities to build separate paths are often limited in city centers due to space constraints and related costs.

Although we cannot deduce a cause and effect relationship, the results let us suggest that if more bicycle paths would be available, more people would be tempted to use the bicycle as a mode of transport. ${ }^{37}$ Although the variance explained by 'bicycle paths' is relatively small, it does not mean that environmental variables (like bicycle paths) are of little importance. It is reasonable to suggest that in terms of promoting cycling, providing more bicycle paths is the most prudently modifiable factor of those investigated. Small changes in relevant environmental factors could influence daily PA patterns (and in particular cycling for transport) of large populations over long periods of time. ${ }^{38}$

When building new bicycle infrastructure, different aspects of the spatial design of networks should be taken into account. First, a network of different types of infrastructure appears necessary to encourage people to initiate cycling. ${ }^{37}$ Simply adding bike lanes to all new major roads is unlikely to achieve high rates of cycling. For people concerned with safety issues and avoiding traffic, a wellconnected network of low-motorized traffic streets, including some 'bicycle boulevards' (roads dedicated exclusively to bicycle use), may be more effective than adding bike lanes on major streets with high volumes of motor vehicle traffic. Int Panis et $\mathrm{al}^{9}$ stress that from a health perspective, people should be encouraged to cycle in streets with as little motorized traffic as possible because air pollution from exhaust could reduce the positive health benefits of cycling. Second, direct routes for cyclists should be provided with as few stops (eg, traffic light) as possible. ${ }^{19}$

The correlates in our models only explain a limited proportion (26\%) of the variance of the dependent variable. It remains likely that unmeasured psychosocial factors beyond the scope of this study may be more important in explaining cycling behavior. ${ }^{20,21}$ Previous research in Flanders, comparing regular commuter cyclists with people who never cycle for transportation, showed that when people live in an environment with adequate bicycle infrastructure, individual determinants (psychosocial, self-efficacy, perceived benefits and barriers) outperform the role of environmental determinants. ${ }^{21}$ Cycling is only moderately associated with the neighborhood in King County, Washington (USA), where bicycle infrastructure is limited..$^{20}$ Moudon et $\mathrm{al}^{16}$ concluded that in those conditions, cycling is an individual choice that is independent from environmental support. Rietveld and Daniel ${ }^{15}$ showed that in the Netherlands, most of the intermunicipality variation in bicycle use is related to physical aspects such as altitude differences and city size, features of the population (share of youngsters) and differences in ethnic composition. Psychosocial interventions will be effective in their ability to increase PA, but only applicable to a limited number of people.

For example the distance between the place of residence and work is one of the most important parameters for deciding whether to cycle. ${ }^{17,28}$ Meteorological conditions and topography are other examples that were not taken into account. Hilly cities will exhibit lower bicycle use. ${ }^{17,19}$

\section{Bicycle Usage and Public Health}

To implement effective noncommunicable disease prevention programs, policy makers need data of physical activity levels and trends. ${ }^{39}$ As mentioned earlier, every adult should therefore accumulate $30 \mathrm{~min}$ of moderate-intensity PA 5 days/week or 20 min of vigorous-intensity PA on 3 days/week, or a combination of moderate- and vigorous-intensity activity. ${ }^{3}$ Converting this recommendation in terms of MET-min/week, all healthy adults should accumulate 450-750 MET-min/week to achieve substantial health benefits. Nevertheless, others have suggested that even half the recommended amount of physical activity (ie, $15 \mathrm{~min}$ per day or 90 min a week of moderate-intensity exercise) can provide significant health benefits. ${ }^{5}$ Specifically for women, Brown et $\mathrm{al}^{40}$ showed in their review protective benefits for cardiovascular disease and diabetes with PA of 240 MET-min/week. The frequency, cycling time per week and MET-min/week recorded in this study indicate that participants perform enough PA to comply with PA and public health guidelines to promote and maintain health (eg, ACSM, ${ }^{3}$ British Association of Sport and Exercise Sciences ${ }^{4}$ ), and reduce the risk of chronic disease and premature death. The intensity of PA is also an important parameter of health benefits. ${ }^{41,42}$ The cycling speed, used in this study as a proxy for the intensity, was comparable with the cycling speed computed in a previous study. ${ }^{11}$ It was shown that the intensity of utilitarian cycling was high enough to meet the ACSM guidelines. ${ }^{3}$

For a better understanding of the hazards and links between health and cycling, exposure-based fatality rates are needed. ${ }^{13}$ Only when we understand the differences in how much people walk, cycle, or travel by car, and then express the risk of injury per unit of exposure, can we measure how safe these activities are and evaluate the specific policies that contribute to improve safety. Our data show that distance, frequency and cycling speed are different between the regions, indicating that even within one country, large differences in the incidence and risk of accidents exist. Indeed, as part of the SHAPES project, de Geus et $\mathrm{al}^{24}$ and Vandenbulcke et $\mathrm{al}^{17}$ recently showed that large differences in accident risks and the severity of the accident exist between the 3 Belgian regions and between the municipalities. Whereas the absolute number of accidents is higher in Flanders, the Brussels-capital region is the region with the highest Incidence Rate (\#accidents $/ 1000 \mathrm{~km}$ cycled). Although the incidence rate is higher in the BCR, the probability to be seriously injured or to die while cycling is lower than in the other regions. 
In the study of Zuurbier et al, ${ }^{41}$ the mean cycling speed in the center of a medium-sized Dutch city $(145,000$ inhabitants) was $12 \mathrm{~km} / \mathrm{hr}$, compared with $15.8 \mathrm{~km} / \mathrm{hr}$ in BCR in this study. As Zuurbier et $\mathrm{al}^{41}$ indicate, this mean cycling speed underestimates minute ventilation (inhaled volume of air) levels and consequently the inhaled dose of air pollutants during cycling. Substituting our more accurate estimates in their calculations may reveal that health impacts of exposure to air pollution are much higher than previously estimated.

\section{External Validity of Bicycle Usage}

The SHAPES online registration system is a rich and detailed travel database and provides a lot of useful information. At the same time, it is likely to be prone to a number of errors and inconsistencies. To test the external validity of our data collection, studies investigating the validity of self-reported cycling characteristics were consulted and a comparison was made between our results and other data collections in Belgium and other commuter cycling studies. ${ }^{8,9}$ As the participants were free to start and stop their participation, not all participants filled out the TDs for 1 whole year. Seventy percent of the included participants filled out more than 3 TDs.

Witlox and Tindemans ${ }^{43}$ and Witlox ${ }^{44}$ indicate that commuters are capable of estimating their travel distance with reliable accuracy. The accuracy of self-reported distances is influenced by the sociodemographic profile of the participants, the characteristics of the trip, and the type of transport mode used. ${ }^{44}$ Witlox and Tindemans ${ }^{43}$ showed that the accuracy of estimating the distance traveled increases with the person's income. In the same study, it was shown that executives and employees report better than retired or unemployed people but that gender does not have any influence on the accuracy of the estimate. It was found that self-reported distances for recurring, regular trips (such as trips to work) were more reliable than other trips, suggesting that repetitiveness of the trip positively influences distance knowledge.

When comparing the mean cycling characteristics from our study with other commuter cycling studies, ${ }^{8,9}$ the mean frequency, time and distance ( $\mathrm{km} /$ trip and $\mathrm{km} /$ week) is slightly higher in this study. This could be explained by the fact that the study of de Geus et $\mathrm{al}^{8}$ and Hendriksen et $\mathrm{al}^{9}$ are intervention studies with untrained subjects who did not cycle to work before the start of the study.

\section{Study Limitations}

Some limitations of this study should be noted. Due to the nature of this study, the study population is self-selective and is composed of regular adult cyclists, which limits the generalizability of the findings. Therefore, the results of this study should be interpreted within the boundaries of its limits [eg, the results may not be (entirely) applicable to younger ( $<18$ years) and older adults ( $>65$ years) and people who cycle only occasionally or start cycling].

Passionate cyclists, who cycle a longer distance and time than occasional cyclists, seem to be more likely to participate. The requirement for e-mail and Internet access limits the applicability to some segments of the population. However, the Federal Public Service (FPS) Economy revealed that $73 \%$ of the households in Belgium had an access to internet in $2010 .{ }^{45}$ As discussed in the Study Population section, our sample includes a higher proportion of people with above-average income and education compared with the general Belgian population of commuter cyclists. ${ }^{16}$ Compared to the NIS ${ }^{16}$ and FPS ${ }^{46}$ data, the BCR is overrepresented and the participants in Flanders and Wallonia constitute an underrepresentation (Supplementary file 2).
The calculated energy expenditure (EE) in this study should not be seen as absolute values but rather as an activity classification. The values do not take into account differences in body mass, adiposity, age, gender, efficiency of movement, geographic and environmental conditions in which the cycling was performed. Individual differences in energy expenditure can be large and the true energy cost for a person may be under- or overestimated compared with the values used in this manuscript.

\section{Conclusions}

Prospective collection of bicycle usage data is essential to improve estimations of the health impact of utilitarian cycling. The SHAPES online registration system was successful in registering bicycle usage data from regular commuter cyclists in Belgium. One thousand one hundred eighty-seven regular commuter cyclists filled out travel diaries covering an average of 387 data collection points per week over 1 year. Regular commuter cyclists commute on average 3.2 times per week to work. This means that they cycle on average 166 minutes per week, covering a distance of $9.04 \mathrm{~km}$ per trip. Men cycle for a longer duration (181 min/week and $138 \mathrm{~min} /$ week, respectively), over longer distances $(61.6 \mathrm{~km} /$ week and 36.3 $\mathrm{km} /$ week, respectively) and at a higher speed $(19.5 \mathrm{~km} / \mathrm{h}$ and 15.5 $\mathrm{km} / \mathrm{h}$, respectively) compared with women. Higher 'age' and 'good health' were associated with more cycling. Large regional differences are present, implying that policy toward cycling should be region specific. Stimulating measures should be specifically aimed at women as this group of commuter's cycle significantly less than men. The results of the SMLR model indicate that bicycle usage is related to the 'level of urbanization of the place of residence,' 'gender,' and the 'presence of bicycle paths.'

The results of this study provide an accurate estimate of some aspects of bicycle usage that are essential to estimate the health benefits and risks of utilitarian cycling among regular Belgian cyclists.

\section{Acknowledgments}

The work reported in this paper was partly financed by the Belgian science policy under the Science for Sustainable Development program (project $n^{\circ}$ : $\mathrm{SD} / \mathrm{HE} / 03$ ) and the Flemish Institute for Technological Research (VITO, Belgium) coordinated research project. The authors wish to thank Dr. Ir Nico Smets for creating the online registration system as well as Eva von Rauch for her guidance in the statistics.

\section{References}

1. Haskell WL, Nelson ME. Physical Activity Guidelines Advisory Committee. Physical Activity Guidelines Advisory Committee Report. Washington, DC: Department of Health and Human Services; 2008. Available at: www.health.gov/paguidelines. 2008.

2. Lee IM, Shiroma EJ, Lobelo F, Puska P, Blair SN, Katzmarzyk PT. Effect of physical inactivity on major non-communicable diseases worldwide: an analysis of burden of disease and life expectancy. Lancet. 2012;380(9838):219-229. PubMed doi:10.1016/S01406736(12)61031-9

3. Haskell WL, Lee IM, Pate RR, et al. Physical activity and public health. Med Sci Sports Exerc. 2007;39(8):1423-1434. PubMed doi:10.1249/ mss.0b013e3180616b27

4. O'Donovan G, Blazevich AJ, Boreham C, et al. The ABC of physical activity for health: a consensus statement from the British Association of Sport and Exercise Sciences. J Sports Sci. 2010;28(6):573-591. PubMed doi:10.1080/02640411003671212 
5. Wen CP, Wai JP, Tsai MK, et al. Minimum amount of physical activity for reduced mortality and extended life expectancy: a prospective cohort study. Lancet. 2011;378(9798):1244-1253. PubMed doi:10.1016/S0140-6736(11)60749-6

6. Oja P, Titze S, Bauman A, et al. Health benefits of cycling: a systematic review. Scand J Med Sci Sports. 2011;21(4):496-509. PubMed doi:10.1111/j.1600-0838.2011.01299.x

7. Oja P, Vuori I, Paronen O. Daily walking and cycling to work: their utility as health-enhancing physical activity. Patient Educ Couns. 1998;33(1, Suppl):S87-S94. PubMed doi:10.1016/S07383991(98)00013-5

8. Hendriksen IJ, Zuiderveld B, Kemper HC, Bezemer PD. Effect of commuter cycling on physical performance of male and female employees. Med Sci Sports Exerc. 2000;32(2):504-510. PubMed doi:10.1097/00005768-200002000-00037

9. de Geus B, Joncheere J, Meeusen R. Commuter cycling: effect on physical performance in untrained men and women in Flanders: minimum dose to improve indexes of fitness. Scand J Med Sci Sports. 2009;19(2):179-187. PubMed doi:10.1111/j.1600-0838.2008.00776.x

10. de Geus B, Van Hoof E, Aerts I, Meeusen R. Cycling to work: influence on indexes of health in untrained men and women in Flanders. Coronary heart disease and quality of life. Scand J Med Sci Sports. 2008;18(4):498-510. PubMed doi:10.1111/j.1600-0838.2007.00729.x

11. de Geus B, De Smet S, Nijs J, Meeusen R. Determining the intensity and energy expenditure during commuter cycling. Br J Sports Med. 2007;41(1):8-12. PubMed doi:10.1136/bjsm.2006.027615

12. Int Panis L, de Geus B, Vandenbulcke G, et al. Exposure to particulate matter in traffic: a comparison of cyclists and car passengers. Atmos Environ. 2010;44(19):2263-2270. doi:10.1016/j. atmosenv.2010.04.028

13. Christie N, Cairns S, Towner E, Ward H. How exposure information can enhance our understanding of child traffic "death leagues". Inj Prev. 2007;13(2):125-129. PubMed doi:10.1136/ip.2006.011692

14. Jacobsen PL. Safety in numbers: more walkers and bicyclists, safer walking and bicycling. Inj Prev. 2003;9(3):205-209. PubMed doi:10.1136/ip.9.3.205

15. Stone M, Broughton J. Getting off your bike: cycling accidents in Great Britain in 1990-1999. Accid Anal Prev. 2003;35(4):549-556. PubMed doi:10.1016/S0001-4575(02)00032-5

16. National Institute for Statistics (NIS), Belgian Federal Science Policy Office. National house hold survey on mobility. Realization and results. Research contract MD/13/036. Brussels: FUNDP-GRT- LV-UIA-IWINS; 2001.

17. Vandenbulcke G, Thomas I, de Geus B, et al. Mapping bicycle use and the risk of accidents for commuters who cycle to work in Belgium. Transp Policy. 2009;16(2):77-87. doi:10.1016/j.tranpol.2009.03.004

18. Winters M, Friesen MC, Koehoorn M, Teschke K. Utilitarian bicycling. a miltilevel analysis of climate and personal influences. Am J Prev Med. 2007;32(1):52-58. PubMed doi:10.1016/j.amepre.2006.08.027

19. Rietveld P, Daniel V. Determinants of bicycle use: do municipal policies matter? Transp Res Part A Policy Pract. 2004;38(7):531-550. doi:10.1016/j.tra.2004.05.003

20. Moudon AV, Lee C, Cheadle AD, et al. Cycling and the built environment, a US perspective. Transport Res D-Tr E. 2005;10(3):245-261. doi:10.1016/j.trd.2005.04.001

21. de Geus B, De Bourdeaudhuij I, Jannes C, Meeusen R. Psychosocial and environmental factors associated with cycling for transport among a working population. Health Educ Res. 2008;23(4):697-708. PubMed doi:10.1093/her/cym055

22. Vandenbulcke G, Dujardin C, Thomas I, de Geus B, Degraeuwe B, Meeusen R, et al. Cycle commuting in Belgium: Spatial determinants and 're-cycling' strategies. Transport Res a-Pol. 2011;45(2):118-37.
23. Aertsens J, de Geus B, Vandenbulcke G, et al. Commuting by bike in Belgium, the costs of minor accidents. Accid Anal Prev. 2010;42(6):2149-2157. PubMed doi:10.1016/j.aap.2010.07.008

24. de Geus B, Vandenbulcke G, Int Panis L, et al. A prospective cohort study on minor accidents involving commuter cyclists in Belgium. Accid Anal Prev. 2012;45:683-693. PubMed doi:10.1016/j. aap.2011.09.045

25. Oja P. Dose response between total volume of physical activity and health and fitness. Med Sci Sports Exerc. 2001;33(6):S428-S37. PubMed doi:10.1097/00005768-200106001-00011

26. Ainsworth BE, Haskell WL, Whitt MC, et al. Compendium of physical activities: an update of activity codes and MET intensities. Med Sci Sports Exerc. 2000;32(9, Suppl):S498-S504. PubMed doi:10.1097/00005768-200009001-00009

27. Giles-Corti B, Timperio A, Bull F, Pikora T. Understanding physical activity environmental correlates: increased specificity for ecological models. Exerc Sport Sci Rev. 2005;33(4):175-181. PubMed doi:10.1097/00003677-200510000-00005

28. Dickinson J, Kingham S, Copsey S, Pearlman Hougie D. Employer travel plans, cycling and gender: will travel plan measures improve the outlook for cycling to work in the UK? Transp Res Part D Transp Environ. 2003;8(1):53-67. doi:10.1016/S1361-9209(02)00018-4

29. Garrard J, Rose G, Lo SK. Promoting transportation cycling for women: the role of bicycle infrastructure. Prev Med. 2008;46(1):5559. PubMed doi:10.1016/j.ypmed.2007.07.010

30. Doherty ST, Aultman-Hall L, Swaynos J. Commuter cyclist accident patterns in Toronto and Ottawa. J Transp Eng. 2000;126(1):21-26. doi:10.1061/(ASCE)0733-947X(2000)126:1(21)

31. Pucher J, Renne JL. Socioeconomics of urban travel: evidence from the 2001 NHTS. Transp Q. 2003;57(3):49-77.

32. MON. Mobiliteitsonderzoek Nederland. Ministerie van Verkeer en Waterstaat; Rijkswaterstaat; Dienst Verkeer en Scheepvaart (200801-01; 2008-12-31). 2008.

33. DNTS. Danish National Travel Survey (TU200610v2) and DTU Transport.; 2010.

34. Hoffman MR, Lambert WE, Peck EG, Mayberry JC. Bicycle commuter injury prevention: it is time to focus on the environment. $J$ Trauma Inj Infect Crit Care. 2010;69(5):1112-1119. PubMed doi:10.1097/ TA.0b013e3181f990a1

35. Berg HY. Reducing crashes and injuries among young drivers: what kind of prevention should we be focusing on? Inj Prev. 2006;12(Suppl 1):i15-i18. PubMed doi:10.1136/ip.2006.012062

36. Vandenbulcke G, Steenberghen T, Thomas I. Accessibility indicators to places and transports: final report. Research Contract AP/10/02A. Belgian Science Policy and FPS Mobility and Transports, Brussels Available online at: http://www.mobilit.fgov.be/fr/index.htm. 2007.

37. Dill J. Bicycling for Transportation and Health: The Role of Infrastructure. J Public Health Policy. 2009;30:S95-S110. PubMed doi:10.1057/ jphp. 2008.56

38. De Bourdeaudhuij I, Sallis JF, Saelens BE. Environmental correlates of physical activity in a sample of Belgian adults. Am J Health Promot. 2003;18(1):83-92. PubMed doi:10.4278/0890-1171-18.1.83

39. Hallal PC, Andersen LB, Bull FC, Guthold R, Haskell W, Ekelund U. Global physical activity levels: surveillance progress, pitfalls, and prospects. Lancet. 2012;380(9838):247-257. PubMed doi:10.1016/ S0140-6736(12)60646-1

40. Brown WJ, Burton NW, Rowan PJ. Updating the evidence on physical activity and health in women. Am J Prev Med. 2007;33(5):404-11. e25.

41. Zuurbier M, Hoek G, Hazel P, Brunekreef B. Minute ventilation of cyclists, car and bus passengers: an experimental study. Environ Health. 2009;8(1):48. PubMed doi:10.1186/1476-069X-8-48 
42. de Hartog JJ, Boogaard H, Nijland H, Hoek G. Do the health benefits of cycling outweigh the risks? Environ Health Perspect. 2010;118(8):1109-1116. PubMed doi:10.1289/ehp.0901747

43. Witlox F, Tindemans H. Evaluating bicycle-car transport mode competitiveness in an urban environment. An activity-based approach. World Transp Policy Pract. 2004;10(4):32-42.

44. Witlox F. Evaluating the reliability of reported distance data in urban travel behaviour analysis. J Transp Geogr. 2007;15(3):172-183. doi:10.1016/j.jtrangeo.2006.02.012
45. Digital FPS. (r)evolution in Belgium-2010. Available online at: http:// statbel.fgov.be/en/binaries/ict2010-en_tcm327-117754.pdf 2010.

46. FPS. Mobility and Transport Diagnistiek woon-ververkeer van 30 juni 2008. Available online at: http://www.mobilit.fgov.be/nl/mobil/ mobaccn/diagnosn.htm.; 2010.

47. IRIS2. Mobiel Brussel-BUV van het Brussels Hoofdstedelijk Gewest, Camille Thiry, nov 2011.; 2011. 